\title{
Eriginal Article
}

\section{Posture Analysis by OWAS Method and Prevalence of Musculoskeletal Disorders among Workers of Sourak Tobacco Factory in 2013}

\author{
Siavash Etemadinezhad ${ }^{1} \quad$ *Fateme Ranjbar ${ }^{2} \quad$ Mina Gorji $^{3}$
}

1- Health Sciences Research Center, Department of Occupational Health, Mazandaran University of Medical Sciences, Sari, Iran.

2- Department of Occupational Health, Mazandaran University of Medical Sciences.

3- Student of Occupational Health, Mazandaran University of Medical Sciences.

\section{*fateme.ranjbar20@yahoo.com}

\begin{abstract}
Background and purpose: Work-related Musculoskeletal Disorder are the most prevalent workrelated disorders and are the main cause of disability among workers. Also these disorders are the main cause of absence from work and lost work hours. These lead to reduction in productivity too.

Materials and Methods: This cross - sectional study was done on 100 workers of Sourak tobacco factory selected randomly. Posture analysis was evaluated by OWAS method and prevalence of musculoskeletal disorders by Nordic questionnaire. The data were analyzed using excel and Spss software version 18.

Results: The mean age of workers was $(43 \pm 3.97)$ year and work experience was 12 years. The prevalence of MSDs was $75 \%$ in the last year the lumber region (55\%), knee (45\%) and shoulders $(37 \%)$ were the most regions of workers complaints. OWAS posture analysis showed that the most postures are critical or need the modification intervention.

Conclusion: The prevalence of musculoskeletal disorders in Sourak tobacco factory is high and the postures are inappropriate. Ergonomic interventional programs as well as workers education are recommended. [Etemadinezhad S. *Ranjbar F. Gorji M. Posture analysis by OWAS method and prevalence of Musculoskeletal Disorders among workers of Sourak tobacco factory in 2013. IJHS 2013; I(2):89-94] http://jhs.mazums.ac.ir
\end{abstract}

Key words: Musculoskeletal Disorders, Nordic questionnaire, OWAS method 


\section{Introduction}

Work-related musculoskeletal disorders are the most prevalent work-related disorders and injuries and the leading cause of disability (1). Despite increasing of mechanization, many occupational activities and work tasks are done by workers which can lead to musculoskeletal disorders. It is the main cause of absence from the work, loss of working hours $(2,3)$, reduction in productivity, increase in costs and workers incapacitation (4). It is one of the main problems of occupational health, worldwide (5).The main causes of WMSDs are inappropriate body postures, manual material handling, repetitive movements and inappropriate design of work stations (4). Most workers have the body posture which can lead to pain/damage in some parts of the body (6). The health ministry of Iran estimates that $76 \%$ of workers have inappropriate body postures (7). $44 \%$ of work-related disorders in America are musculoskeletal disorders (8). Social insurance organization of Iran reported the musculoskeletal disorders as the most cause of medical commission referral in 2000, also, the cause of $14.4 \%$ of total disability from 1991 to 1994(9). These are related to nature of the work as well as old technology and insufficiency of administrative controls the aim of this study was determination the prevalence of musculoskeletal disorders, by Nordic method and the risk factors of them by owas method. These are the first steps for ergonomic interventions and modifications.

\section{Materials and Methods}

The descriptive study was proposed in Sourak tobacco factory which have 247 workers. 100 workers were selected randomly and the prevalence of musculoskeletal disorders was determined by Nordic questionnaire. This questionnaire has been designed by Kurika and his colleague in Scandinavian industrial hygiene institute in 1987and is used for epidemiologic studies worldwide. In this questionnaire the musculoskeletal system is divided to 9 regions as neck, shoulders, elbows, wrists/hands, upper back, low back, knees, and ankles/foots. The researcher completed the questionnaires by interview with workers. Posture analysis was done using OWAS (Ovako Working Posture Analyzing System) method which was designed by Finish occupational health and safety in 1992 and is used worldwide since that time. In this method 4 codes are determined, according to the body postures and movements and the amounts of material handling, these codes shows the amount of musculoskeletal risk level and the priority of ergonomic interventions and modifications. Researcher completed the forms and determined the codes by observation of 97 work stations. Data were analyzed by excel and Spss version 18 software. 


\section{Results}

The mean age of the workers was $(40 \pm 3.9)$ years and the mean of the work experience in tobacco factory was $10(+-2)$ years. According to the Nordic questionnaire $75 \%$ of workers declared that they have had the symptoms of musculoskeletal disorders in at least one mentioned body regions in the past year. The most prevalent symptoms were in the low back (55\%), knees (45\%) and shoulders $(37 \%)$. Table 1 shows the prevalence of the musculoskeletal symptoms in nine body regions of workers in the past year. Posture analysis by OWAS method in 97 work station showed that 30 body postures(30.9\%) got the code number 1(normal), and there is no need to modification. 36 body postures $(37.1 \%)$ got the code number 2(stressful), and have to be modified in the future. 26 body postures (26.8\%) got the code number 3(harmful) and must be modified as soon as possible. 5 body postures $(5.1 \%)$ got the code number 4(very harmful) and the work must be ceased and the modification must be done immediately. Table 2 shows the results of posture analysis of 97 work station in Sourak tobacco factory. The leading causes of the inappropriate postures were heavy lifting, inappropriate height of work level which leads to lumbar flexion and inappropriate lower extremity postures.

Table 1. The prevalence of musculoskeletal disorders of Sourak tobacco factory workers In the past year $(n=100)$

\begin{tabular}{ccccccccc}
\hline Neck & Shoulder & Elbow & Wrist/hand & $\begin{array}{c}\text { Upper } \\
\text { back }\end{array}$ & Lumbar & $\begin{array}{c}\text { One or } \\
\text { both } \\
\text { hips/thighs }\end{array}$ & $\begin{array}{c}\text { One or } \\
\text { both } \\
\text { knees }\end{array}$ & $\begin{array}{c}\text { One or } \\
\text { both } \\
\text { ankle/feet }\end{array}$ \\
\hline 31 & 37 & 24 & 20 & 23 & 55 & 26 & 45 & 25 \\
\hline
\end{tabular}

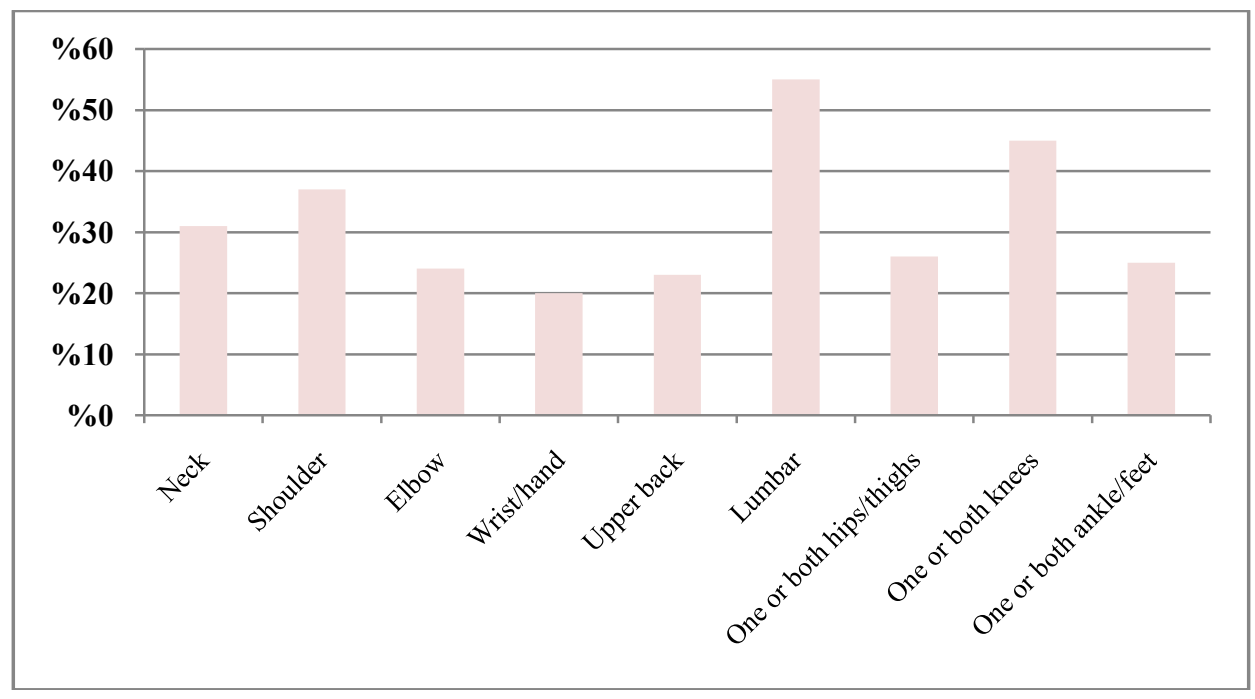

Graph1. Frequency of musculoskeletal disorders in 9 areas of the body in the last year 
Table 2. Frequency and action Categories different postures of body

\begin{tabular}{cccc}
\hline & posture & Frequency & $\begin{array}{c}\text { Action } \\
\text { Categories }\end{array}$ \\
& straight & 26 & 1 \\
Lumbar & Twisting & 53 & 2 \\
& Bending \& Twisting & 7 & 3 \\
Upper Extremities & Both Arms below shoulder level & 71 & 4 \\
& One Arm above shoulder level & 15 & 1 \\
& Both Arms above shoulder level & 12 & 2 \\
& sitting & 13 & 3 \\
& Standing with straight lower & 31 & 1 \\
& limbs & & 1 \\
& Standing with one straight lower & 22 & 2 \\
& limb & & 3 \\
& Standing with flexed knee & 14 & 3 \\
& squatting & 6 & 4 \\
& Kneeling & 1 & 2 \\
\hline
\end{tabular}

\section{Discussion}

This study revealed that the prevalence of musculoskeletal disorders among Sourak tobacco factory workers is high and $75 \%$ of workers have had the symptoms in at least one of their body region in the past year. The results of this study are close to the many studies that have been done in other industries, although there are some differences in prevalence and regions of the complaint. In Sourak tobacco factory, the most prevalent regions of musculoskeletal complaints were in low back (55\%), knees (45\%) and shoulders (37\%) by Nordic questionnaire. In Mostaghasi study on the 70 agricultural tools producing workers in 2011, the prevalence of musculoskeletal disorders was $40.3 \%$ and low back $(12.8 \%)$, knees $(8.7 \%)$ and hands $(7.8 \%)$ were the most prevalent regions (11). In Choobineh study on 116 workers of Shiraz sugar factory in 2009 the prevalence of low back pain was $54.3 \%$ and shoulders pain was $48.3 \%$ (12). The results of the study performed by Ismail on the montage workers in Malaysia in 2009 determined the prevalence of the symptoms in low back $(32.9 \%)$, in knees $(26.4 \%)$ and in shoulders (18.8\%) (13). In aghilinezhad study on 1439 steel industry workers in Tehran in 2011, the prevalence of musculoskeletal disorders was $61 \%$ and the low back (63.8\%), knees $(45.3 \%)$ and neck $(39.7 \%)$ were the most regions of complaint investigated by Nordic questionnaire (14). In The study of Spallak performed on 209 professional computer users in Germany in 2010.The prevalence of musculoskeletal disorders was estimated $67 \%$. The most prevalent regions of symptoms were low back (40\%), shoulders (40\%) and knees (15\%).According to our study and the mentioned studies the most prevalent disorder 
is low back pain. Posture analysis by owas method in 97 work station In sourak tobacco factory showed that $30.9 \%$ body postures were normal, $37.1 \%$ body postures were stressful, $26.8 \%$ body postures were harmful and $5.1 \%$ body postures were very harmful .Owas posture analysis in 20 welders of oil industry performed by Soltani in 2010 showed that $58.5 \%$ of welders were in normal posture, $34.7 \%$ were in stressful posture, $4 \%$ were in harmful posture and $2.5 \%$ were in very harmful posture (16). In the other similar study performed by Habibi in Mahyaman factory in Isfahan, $72.2 \%$ of the workers were in normal posture, $21.2 \%$ in stressful posture, $2.7 \%$ in harmful posture and $3.5 \%$ in very harmful posture (17). Comparing these results to our investigation shows that the workers of Sourak tobacco factory are at higher risk for developing musculoskeletal disorders. According to our results, ergonomic interventional programs seem to be necessary. We recommend provide and use of ergonomic chairs, frequent rests, modification in manual material handling, workers education as well as engineering controls.

\section{Acknowledgement}

The researchers would like to appreciate the managers and workers of Sourak tobacco factory for their cooperation and the student research committee for the financial support.

\section{References}

1.Gordan C.Johnson EW, Gatens PF,A SH ton JJ Wrist ratio correlation with carpal tunnel syndrome industry. Am J Phys Med Rehbil 1988;(6):270-277.

2.Waters TR, Puts -Anderson V. Occupational Ergonomics. Newyork: Dekker Publication; 1996. 3.Ohlsson K,Attewell R,Skerfeving S .Selfreported symptoms in the neck and upper limbs of female assembly workers .Scandinavian journal of work Environment Health 1989;15:75-80.

4.Holder NI,Clark JM, Di Blasio JM,et al. cause, prevalence ,and response to occupational musculoskeletal injuries reported by physical therapists and physical therapist .Phys the 1999;79:642-652.

5.Kibom A. Editorial/Prevention of work-related musculoskeletal disorders in the workplace. Into $\mathrm{J}$ Indi Erg on 1998; 21:1-3.

6.Choobine A. Methods of posture assessment in occupational ergonomics. 1th Ed. Fanavaran, 2004:6[Persian].

7.Sadeghi F, Asilian H, Barati L. Evaluation of the body posture of factory workers in Ahwaz Rolling Industry. Behbood Journal 2006; 6(1): 3441[Persian].

8.Matila M,Vilkki M.OWAS Methods In: The occupational Ergonomics Handbook Karwowski w, Marras WS. Editor .Boca Raton, FA, USA: CRC Press LLC, 1999:447-59.

9.Social Security organization. Treatment vice chancellor A Report of statistics of medical commissions.2000.[Persian].

10.Kurinka I, Jonsson B ,Kilbom A, Vinter berg $\mathrm{H}$, Bering -Sorensen F, Anderson $\mathrm{G}$ and Jorgensen.Standardized Nordic Questionnaires for the analysis of musculoskeletal symptoms. Applied Ergonomics 1987; 18(3), 233-7.

11.Choobineh A .Method of posture evaluation in the occupational ergonomics. Hamden: Fanavaran Publication, 2004[Persian]. 
12.Mostaghaci M, Davari MH, Salimi Z ,Javaheri M, Hoseininejad SF, Salehi M,et al. Evaluation of the musculoskeletal disorders and its risk factors in the workers of an agricultural equipmentmanufacturing plant. Occupational medicine Quarterly Journal 2012; 3(3):19-25[Persian].

13. Ismail AR,Yeo ML,Haniff MHM,Zulkifli R,Deros BM,Makhtar NK. Assessment of postural loading among the assembly operators: A case study at Malaysian Automotive Industry. European journal of scientific researcher 2009;30:224-35.

14.Aghilinejad M, Choobineh A. Prevalence of Musculoskeletal Disorders among Iranian Steel Workers. Iranian Red Crescent Medical Journal 2012;14(4):198-203.
15.Spallek M, Kuhn W, Uibell S,et al. workrelated musculoskeletal disorders in the automotive industry due to repetitive workimplications for rehabilitation. Journal of occupational medicine and toxicology 2010; 5:6. 16.Faramarzi R,Dehghani y. Posture Analysis by OWAS method among Welders. Journal of Occupational Medicine 2011;3(1):34-39.

17.Habibi A, Farokhi Z. Posture Analysis by OWAS method among workers of Mahyaman factory. Fourth Conference Occupational Health Iran-Hamadan 2004;457-482. 